\title{
A comparison between spironolactone and spironolactone plus finasteride in the treatment of hirsutism
}

\author{
Fahrettin Keleştimur ${ }^{1}$, Hatice Everest ${ }^{1}$, Kürşad Ünlühızarcı ${ }^{1}$, Fahri Bayram ${ }^{1}$ and Yılmaz Şahin ${ }^{2}$ \\ Departments of ${ }^{1}$ Endocrinology and ${ }^{2}$ Obstetrics and Gynecology, Erciyes University Medical School, Kayseri, Turkey \\ (Correspondence should be addressed to F Keleștimur; Email: fktimur@erciyes.edu.tr)
}

\begin{abstract}
Objective: To compare the clinical efficacy and safety of the combination of spironolactone $(100 \mathrm{mg} /$ day $)$ plus finasteride $(5 \mathrm{mg} /$ day $)$ and spironolactone $(100 \mathrm{mg} /$ day $)$ alone in the treatment of hirsutism.

Patients and measurements: Sixty-five hirsute women were randomly assigned to one of these two treatment groups. Hirsutism score was measured according to the modified Ferriman-Gallwey scoring system. Baseline and post-treatment assessments were carried out in each subject by an investigator blinded to the therapy. Both groups had similar demographic properties at baseline. The serum levels of total and free testosterone, dehydroepiandrosterone sulphate and sex hormone-binding globulin were measured at the beginning and after 1 year of therapy. Blood chemistry and side-effects were evaluated during the study. Hirsutism scores were decreased significantly in both groups at the end of the year.

Results: The mean percentage change in hirsutism scores from baseline in the spironolactone plus finasteride-treated group $(51.3 \%)$ was significantly $(P<0.005)$ higher than in the group treated with spironolactone alone $(36.6 \%)$. Patients from both treatment groups experienced similar sideeffects.

Conclusions: We have concluded that a combination of spironolactone plus finasteride is a safe and effective therapy in the treatment of hirsutism.
\end{abstract}

European Journal of Endocrinology 150 351-354

\section{Introduction}

Hirsutism is defined as an excess of body hair with a male distribution. It results from an increase in circulating androgen concentrations, an increase in the sensitivity of the pilosebaceous unit to normal androgen concentrations or a combination of these factors (1). Hirsutism is a very common clinical problem in daily practice and, in addition to non-pharmacological interventions, a pharmacological approach is often required in order to suppress androgen production and/or action in patients with hirsutism. Anti-androgen drugs, usually in association with non-androgenic oral contraceptive therapy, are the treatment of choice in most patients $(1,2)$.

Spironolactone is an effective agent for the treatment of hirsutism $(3,4)$. It is an anti-androgen that competes with dihydrotestosterone (DHT) at the androgen receptor level. It also increases the metabolic clearance of testosterone and inhibits androgen production (5). Finasteride is a very potent competitive inhibitor of the type 2 isoenzyme of $5 \alpha$-reductase and this enzyme is responsible for the conversion of testosterone to the active metabolite $\mathrm{DHT}(6,7)$. Anti-androgens have been given in combination with oral contraceptives in several studies $(8-10)$ but there are insufficient data about the effects of combination anti-androgen therapy in women with hirsutism. Our preliminary results have shown that a combination of spironolactone plus finasteride is more effective than spironolactone alone after 6 months of the therapy (11). In this study, we aimed to compare the clinical efficacy and safety of the combination of spironolactone and finasteride with spironolactone alone and to verify whether extending the duration of the combination therapy is more effective.

\section{Patients and measurements}

Sixty-five patients were recruited into the study from the Endocrinology Outpatient Clinic of Erciyes University Hospital. Each patient gave her informed consent and the study was approved by the Ethical Committee of Erciyes University. Patients with Cushing's syndrome, androgen-secreting tumors and prolactinoma were excluded by appropriate tests and radiological investigations. Those with congenital adrenal hyperplasia, 
due to either 21-hydroxylase or 11 $\beta$-hydroxylase deficiency were excluded by adrenocorticotrophin (Synacthen (0.25 mg i.v.); Novartis, Basel, Switzerland) stimulation test as previously described (12). The hirsutism score was graded according to the modified Ferriman-Gallwey scoring system (13). The hirsute patients (Ferriman-Gallwey score $>8$ ) were randomly divided into two groups.

The study was conducted in a population of unselected women with moderate to severe hirsutism. Thirty-four women had polycystic ovary syndrome diagnosed according to National Institute of Health/National Institute of Child Health and Human Development (NICHHD) criteria (14). Thirty-two patients (group 1) were treated with spironolactone $(100 \mathrm{mg} /$ day $)$ alone and 33 patients (group 2) were treated with spironolactone (Ali Raif, Turkey) (100 mg/day) plus finasteride (Merck-Sharpe-Dohme, UK) (5 mg/day). The patients were randomized in an alternating sequence. The potential risks of these drugs were explained to the patients and sexually active women were advised to use barrier contraceptive methods or intrauterine devices because of possible male fetus feminization. Hirsutism scores were evaluated at the beginning and at the end of the first year by the same observer (F K) who was not aware of the drug that had been given to the patients. Patients were instructed to report any adverse event during the treatment period and they were invited to attend monthly to check blood chemistry and complete blood count. The treating physician (K Ü) and the observer who scored were different. For at least 6 months before the study none of the patients had been using any drug known to interfere with hormone levels. Patients were instructed not to alter their usual eating habits and physical activity during the study.

Serum hormone levels were drawn after an overnight fast in the follicular phase of the menstrual cycle and measurements were performed at the beginning and at the end of the study. Serum samples were stored at $-20^{\circ} \mathrm{C}$ until assayed. Serum follicle-stimulating hormone (FSH; ACS 180; Bayer, New York, NY, USA) and luteinizing hormone (LH; ACS 180; Bayer) levels were determined by an automated chemiluminescence system, serum total testosterone (DSL-4000; DSL, Webster, TX, USA), free testosterone (DSL-4900; DSL) and dehydroepiandrosterone sulphate (DHEAS; Immunotech, Marseille, France) levels were measured by RIA and sex hormone-binding globulin (SHBG) levels were measured by IRMA (Orion Diagnostica, Espoo, Finland) using commercial kits. The intraassay and interassay coefficients of variation were: 2.8 and $4.6 \%$ for FSH, 4.7 and $6.3 \%$ for $\mathrm{LH}, 8.1$ and $9.1 \%$ for total testosterone, 3.7 and $7.9 \%$ for free testosterone, 5.6 and $4.1 \%$ for DHEAS and 4.0 and $5.5 \%$ for SHBG.

Student's unpaired $t$-test was used for comparisons between the groups. The paired $t$-test was performed to compare the changes in basal hirsutism score and hormone levels within each treatment group. Values are expressed as means \pm s.e.m. A $P$ value $<0.05$ was considered as statistically significant.

\section{Results}

The mean ages of the patients in group $1(20.7 \pm 0.5$ years) and group 2 (20.9 \pm 0.3 years) were similar. The mean body mass index (BMI; $\mathrm{kg} / \mathrm{m}^{2}$ ) was also simi$\operatorname{lar}(23.5 \pm 0.7$ vs $23.8 \pm 0.6)$ in both group 1 and group 2 respectively. Patients had similar hirsutism scores and serum androgen levels at the beginning of the therapy. Ferriman-Gallwey scores declined significantly in both groups during treatment. Combination therapy resulted in more significant percent changes in the hirsutism score of the patients. Hirsutism scores, FSH, LH, total and free testosterone, DHEAS and SHBG levels before and after therapy are shown in Table 1. Free testosterone showed a significant $(P<0.005)$ decrease in group 2 and SHBG showed a significant $(P<0.005)$ increase in group 1 patients. General linear model repeated measure was performed for multiple comparisons. BMI- and SHBG-adjusted values for free testosterone and BMI-adjusted SHBG levels showed similar results in terms of statistical significance. The hirsutism score declined significantly at the end of 1 year $(P<0.005)$ in both groups. BMI and actual hirsutism scores were not significantly different in either treatment group at the end of the study. The reductions in hirsutism score (\% of the baseline) at 1 year were significantly higher $(51.3 \%)$ in group 2 than in

Table 1 Hirsutism scores and hormonal values before and after (group 1) spironolactone (100 mg/day) alone $(n=32)$ and (group 2) spironolactone $(100 \mathrm{mg} /$ day) plus finasteride $(5 \mathrm{mg} /$ day $)$ treatment $(n=33)$. Values are means \pm S.E.M.

\begin{tabular}{|c|c|c|}
\hline Parameters & Baseline & Year 1 \\
\hline \multicolumn{3}{|c|}{ Ferriman-Gallwey score } \\
\hline Group 1 & $23.0 \pm 1.1$ & $14.7 \pm 1.0 *$ \\
\hline Group 2 & $26.0 \pm 1.0$ & $12.8 \pm 0.9^{\star}$ \\
\hline \multicolumn{3}{|l|}{$\mathrm{FSH}(\mathrm{mlU} / \mathrm{ml})$} \\
\hline Group 1 & $5.3 \pm 0.3$ & $5.7 \pm 0.3$ \\
\hline Group 2 & $6.0 \pm 0.4$ & $9.9 \pm 3.1$ \\
\hline \multicolumn{3}{|l|}{$\mathrm{LH}(\mathrm{mlU} / \mathrm{ml})$} \\
\hline Group 1 & $7.9 \pm 1.0$ & $6.1 \pm 0.5$ \\
\hline Group 2 & $6.4 \pm 1.0$ & $7.1 \pm 0.8$ \\
\hline \multicolumn{3}{|c|}{ Free testosterone $(\mathrm{pg} / \mathrm{ml})$} \\
\hline Group 1 & $4.1 \pm 0.4$ & $3.4 \pm 0.5$ \\
\hline Group 2 & $4.0 \pm 0.3$ & $3.0 \pm 0.2^{*}$ \\
\hline \multicolumn{3}{|c|}{ Total testosterone (ng/dl) } \\
\hline Group 1 & $87.6 \pm 8.7$ & $68.8 \pm 4.0$ \\
\hline Group 2 & $80.2 \pm 7.3$ & $73.5 \pm 4.4$ \\
\hline \multicolumn{3}{|c|}{ DHEAS (ng/ml) } \\
\hline Group 1 & $3063.4 \pm 221.4$ & $3422.0 \pm 176.5$ \\
\hline Group 2 & $3375.4 \pm 264.6$ & $3435.5 \pm 206.6$ \\
\hline \multicolumn{3}{|c|}{ SHBG $(\mathrm{nmol} / \mathrm{l})$} \\
\hline Group 1 & $42.8 \pm 3.1$ & $56.8 \pm 2.6^{*}$ \\
\hline Group 2 & $42.9 \pm 3.9$ & $49.0 \pm 3.2$ \\
\hline
\end{tabular}

${ }^{*} P<0.005$ compared with baseline. 
group $1(36.6 \%)$. Safety parameters in terms of blood chemistry and any drug reaction did not show significant changes in any subject during the study period and there were no side-effects requiring cessation of therapy in either treatment group; however, $17(60.7 \%)$ out of 28 and $9(47.3 \%)$ out of 19 patients whose menses were formerly regular had polymenorrhea in group 1 and group 2 respectively.

\section{Discussion}

Pharmacological treatment of hirsutism is directed at slowing the growth of new hair and the options are anti-androgens such as finasteride, spironolactone or flutamide, combined oral contraceptive pill with or without anti-androgen agent, gonadotrophin-releasing hormone analogues and recently insulin sensitizers $(1,15,16)$. Flutamide is a non-steroidal compound which seems to act only at the androgen receptor site and is therefore considered to be a pure anti-androgen (17). This drug has been succesfully evaluated in the management of hirsutism $(18-20)$ but it is not recommended as a first-line approach because of liver toxicity (1).

Many studies have clearly established that both spironolactone and finasteride have beneficial effects in the management of women with hirsutism $(3,4$, $15,18,21-26)$. Although both agents are classified as anti-androgen drugs, there are important differences in their mechanisms of action. Spironolactone acts by competing with DHT at the receptor level. It has been used in the treatment of hirsutism in doses ranging from 50 to $400 \mathrm{mg} /$ day (5). It inhibits androgen production by inhibiting cytochrome $\mathrm{P} 450$, particularly at high doses (27). On the other hand, finasteride has no effect on DHT receptors or any known effect on steroid biosynthesis. Finasteride blocks the conversion of testosterone to the more potent DHT by $5 \alpha$-reductase. Since these drugs have different mechanisms of actions we thought that a combination might be more effective than one drug alone in the treatment of hirsutism. We have previously shown that combination therapies of various anti-androgen drugs such as spironolactone or finasteride with ethinyl estradiol $35 \mu \mathrm{g}$ plus cyproterone acetate $2 \mathrm{mg}$ (Diane 35 , Merck-Sharpe-Dohme, UK) are more effective than Diane 35 alone $(8,9)$. Despite the widespread use of spironolactone or finasteride, the effects of a combination of both agents have not been investigated so far. Anti-androgen drugs are good alternatives for women who have a contraindication to oestrogens but the effects of their combination have not been investigated extensively. The current report makes our preliminary results clearer and confirms the results of the preceding study (11) in terms of safety and effectiveness. However, even though the observer was blinded, assessment of hirsutism only by the Ferriman-Gallwey score is the main limitation of this study since this scoring system is a semiquantative and subjective method.

Although the mean hirsutism scores of the patients improved significantly, free testosterone levels declined slightly in women treated with spironolactone. This confirms that the anti-androgenic effect of spironolactone is primarily related to its peripheral effect. This result is also compatible with the suggestion that the reduction in hirsutism scores did not correlate with the changes in androgen levels (28). In this study, 1 year of treatment with a combination of spironolactone plus finasteride resulted in significantly decreased free testosterone levels. This effect seems to be a direct effect, since SHBG levels were not changed significantly before and after treatment. Reduction of free testosterone levels with a combination of spironolactone and finasteride and the role of the combination in the improvement of the hirsutism score remain to be confirmed.

After 1 year of treatment, DHEAS levels were not significantly different in both groups. It has been shown that DHEAS levels do not change after spironolactone or finasteride therapy $(3,29)$. Our results showed that the additon of finasteride did not affect DHEAS levels significantly. Spironolactone therapy resulted in significantly increased SHBG levels at the end of the treatment period. The effect of spironolactone on SHBG levels has not been established previously and there is no clear explanation for this improvement in our study. To date, spironolactone appears to be a relatively safe drug. Polymenorrhea, which is a well-known sideeffect of the drug, was $60.7 \%$ in the group given spironolactone alone in this study. The prevalence of polymenorrhea in the spironolactone plus finasteride-treated group was surprisingly lower at $47.3 \%$. It seems that the addition of finasteride to spironolactone leads to less frequent menstrual disturbance, which is the most frequent side-effect of spironolactone and sometimes results in the cessation of treatment in women with hirsutism.

In conclusion, this study has demonstrated that a combination of spironolactone plus finasteride is effective and safe in the treatment of hirsutism. Percent change in the Ferriman-Gallwey score from baseline at the end of 1 year was higher in patients treated with the combination of spironolactone and finasteride. We consider that combined anti-androgen drugs with different mechanisms of action may be an alternative and useful therapy in the management of hirsutism.

\section{Acknowledgement}

This work was supported by research grants of Erciyes University Medical School (2000-38).

\section{References}

1 Conn JJ \& Jacobs HS. The clinical management of hirsutism. European Journal of Endocrinology 1997136 339-348. 
2 Rittmaster RS. Medical treatment of androgen-dependent hirsutism. Journal of Clinical Endocrinology and Metabolism $1995 \mathbf{8 0}$ 2559-2563.

3 Erenus M, Yücelten D, Durmuşoğlu F \& Gürbüz O. Comparison of finasteride versus spironolactone in the treatment of idiopathic hirsutism. Fertility and Sterility $1997 \mathbf{6 8} 1000-1003$.

4 Shaw JC. Spironolactone in dermatologic therapy. Journal of the American Academy of Dermatology 199124 236-243.

5 McMullen GR \& Van Herle AJ. Hirsutism and the effectiveness of spironolactone in its management. Journal of Endocrinological Investigation $199316925-932$.

6 Jenkins EP, Andersson S, Imperato-McGinley J, Wilson JD \& Russell DW. Genetic and pharmacological evidence for more than one human steroid 5- $\alpha$ reductase. Journal of Clinical Investigation 199289 293-300.

7 Ciotta L, Cianci A, Calogero AE, Palumbo MA, Marletta E, Sciuto A et al. Clinical and endocrine effects of finasteride, a 5 alphareductase inhibitor, in women with idiopathic hirsutism. Fertility and Sterility $199564299-306$.

8 Keleştimur F \& Şahin Y. Comparison of Diane 35 and Diane 35 plus spironolactone in the treatment of hirsutism. Fertility and Sterility $19986966-69$.

9 Şahin Y, Dilber S \& Keleştimur F. Comparison of Diane 35 and Diane 35 plus finasteride in the treatment of hirsutism. Fertility and Sterility 200175 496-500.

10 Pittaway DE, Maxson WS \& Wentz AC. Spironolactone in combination drug therapy for unresponsive hirsutism. Fertility and Sterility $1985 \mathbf{4 3} 878-882$.

11 Ünlühızarcı K, Everest H, Bayram F \& Keleştimur F. Comparison of spironolactone and spironolactone plus finasteride in the treatment of hirsutism. Fertility and Sterility 200278 1331-1333.

12 Keleştimur F, Şahin Y, Ayata D \& Tutuş A. The prevalence of nonclassic adrenal hyperplasia due to $11 \beta$-hydroxylase deficiency among hirsute women in a Turkish population. Clinical Endocrinology $199645381-384$.

13 Hatch R, Rosenfield RL, Kim MH \& Tredway D. Hirsutism: implications, etiology and management. American Journal of Obstetrics and Gynecology $1981140815-830$.

14 Zawadki JK \& Dunaif A. Diagnostic criteria for polycystic ovary syndrome: towards a rational approach. In Polycystic Ovary Syndrome, pp 377-384. Eds Dunaif A, Givens JR, Haseltine F \& Merriam GR. Boston: Blackwell, 1992.

15 AACE Hyperandrogenism Guidelines, American Association of Clinical Endocrinologists medical guidelines for clinical practice for the diagnosis and treatment of hyperandrogenic disorders. Endocrine Practice 20017 121-134.

16 Bayram F, Ünlühızarcı K \& Keleştimur F. Potential utility of insulin sensitizers in the treatment of patients with polycystic ovary syndrome. Treatments in Endocrinology 20021 45-53.

17 Simard J, Luthy I, Guay J, Belanger A \& Labrie F. Characteristics of interaction of the antiandrogen flutamide with the androgen receptor in various target tissues. Molecular and Cellular Endocrinology $1986 \mathbf{4 4} 261-270$.

18 Moghetti P, Tosi F, Tosti A, Negri C, Misciali C, Perrone P et al. Comparison of spironolactone, flutamide, and finasteride efficacy in the treatment of hirsutism: a randomized, double blind, placebo-controlled trial. Journal of Clinical Endocrinology and Metabolism 200085 89-94.

19 Müderris II, Bayram F, Şahin Y, Keleştimur F, Tutuş A \& Ayata D. The efficacy of $250 \mathrm{mg} /$ day flutamide in the treatment of patients with hirsutism. Fertility and Sterility 199666 220-222.

20 Müderris II, Bayram F \& Güven M. A prospective, randomized trial comparing flutamide $(250 \mathrm{mg} /$ day $)$ and finasteride $(5 \mathrm{mg} /$ day) in the treatment of hirsutism. Fertility and Sterility 200073 984-987.

21 Bayram F, Müderris II, Şahin Y \& Keleştimur F. Finasteride treatment for one year in 35 hirsute patients. Experimental and Clinical Endocrinology and Diabetes 1999107 195-197.

22 Crosby PDA \& Rittmaster RS. Predictors of clinical response in hirsute women treated with spironolactone. Fertility and Sterility 199155 1076-1081.

23 Wong IL, Morris RS, Chang L, Spahn M, Stanczyk FZ \& Lobo R. A prospective randomized trial comparing finasteride to spironolactone in the treatment of hirsute women. Journal of Clinical Endocrinology and Metabolism 199580 223-238.

24 Castello R, Tosi F, Perrone F, Negri C, Muggeo M \& Moghetti P. Outcome of long term treatment with the $5 \alpha$-reductase inhibitor of finasteride in idiopathic hirsutism: clinical and hormonal effects during a 1-year course of therapy and 1-year follow-up. Fertility and Sterility $1996 \mathbf{6 6} 734-740$.

25 Şahin Y, Bayram F, Keleştimur F \& Müderris I. Comparison of cyproterone acetate plus ethinyl estradiol and finasteride in the treatment of hirsutism. Journal of Endocrinological Investigation $199821348-352$.

26 Bayram F, Müderris I, Güven M \& Keleştimur F. Comparison of high-dose finasteride ( $5 \mathrm{mg} /$ day) versus low-dose finasteride $(2.5 \mathrm{mg} /$ day $)$ in the treatment of hirsutism. European Journal of Endocrinology $2002147467-471$.

27 Lobo RA, Shoupe D, Serafini P, Brinton D \& Horton R. The effects of two doses of spironolactone on serum androgens and anagen hair in hirsute women. Fertility and Sterility 198543 200-205.

28 Carmina E \& Lobo RA. Peripheral androgen blockade versus glandular androgen suppression in the treatment of hirsutism. Obstetrics and Gynecology 199178 845-849.

29 Schriock EA \& Schriock ED. Treatment of hirsutism. Clinical Obstetrics and Gynecology $199134852-863$.

Received 2 September 2003

Accepted 12 November 2003 